\title{
Primary Care Doctor Characteristics That Determine the Use of Teleconsultations in the Catalan Public Health System: Retrospective Descriptive Cross-Sectional Study
}

Oscar Solans Fernández ${ }^{1}$, MD; Francesc López Seguí ${ }^{2,3}$, MSc; Josep Vidal-Alaball ${ }^{4,5}$, MD, PhD; Josep Maria Bonet Simo $^{1}$, MD; Oscar Hernandez Vian ${ }^{1}$, MSc, MPhil; Pascual Roig Cabo ${ }^{1}, \mathrm{MD}$; Marta Carrasco Hernandez ${ }^{6}$, MSc; Carmen Olmos Dominguez ${ }^{1}$, MSc, MD; Xavier Alzaga Reig ${ }^{1}$, MD; Yesika Díaz Rodríguez ${ }^{6}$, BSc; Manuel Medina Peralta $^{6}$, MD; Eduardo Hermosilla ${ }^{6}$, BSc; Nuria Martínez León ${ }^{1}$, MD; Nuria Guimferrer ${ }^{1}$, MD; Mercedes Abizanda González $^{7}, \mathrm{MD}$; Francesc García Cuyàs ${ }^{8}, \mathrm{MD}, \mathrm{PhD}$; Pol Pérez Sust ${ }^{1}$, MSc

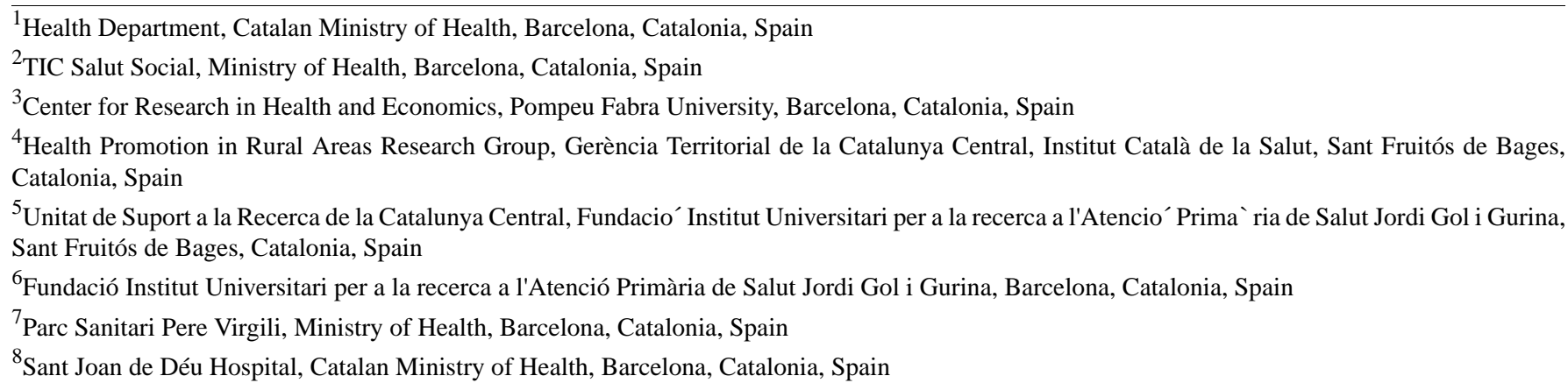

\section{Corresponding Author:}

Josep Vidal-Alaball, MD, PhD

Health Promotion in Rural Areas Research Group

Gerència Territorial de la Catalunya Central

Institut Català de la Salut

C Pica d'Estats, 13-15

Sant Fruitós de Bages, Catalonia

Spain

Phone: 34936930040

Email: jvidal.cc.ics@gencat.cat

\section{Abstract}

Background: eConsulta is a tele-consultation service involving doctors and patients, and is part of Catalonia's public health information technology system. The service has been in operation since the end of 2015 as an adjunct to face-to-face consultations. A key factor in understanding the barriers and facilitators to the acceptance of the tool is understanding the sociodemographic characteristics of general practitioners who determine its use.

Objective: This study aimed to analyze the sociodemographic factors that affect the likelihood of doctors using eConsulta.

Methods: A retrospective cross-sectional analysis of administrative data was used to perform a multivariate logistic regression analysis on the use of eConsulta in relation to sociodemographic variables.

Results: The model shows that the doctors who use eConsulta are 45-54 years of age, score higher than the 80th percentile on the quality of care index, have a high degree of accessibility, are involved in teaching, and work on a health team in a high socioeconomic urban setting.

Conclusions: The results suggest that certain sociodemographic characteristics associated with general practitioners determine whether they use eConsulta. These results must be taken into account if its deployment is to be encouraged in the context of a public health system. 


\section{KEYWORDS}

tele-medicine; tele-consultation; remote consultation; primary care; general practitioners

\section{Introduction}

The use of tele-consulting, synchronous or asynchronous consultation using information and communication technologies (ICT) to omit geographical and functional distance between general practitioners and citizens in primary health care, is widespread in both public [1,2] and private [3] medicine. Although various studies suggest it is beneficial in certain contexts such as the monitoring of diabetes, heart disease, and high blood pressure [4,5] and well accepted by patients [6], its uptake remains low [7], and there are difficulties facing its use in clinical practice $[8,9]$. Some studies have pointed out that these difficulties may be due to a lack of focus in the implementation of these interventions [10] (ie, doctors do not see them as effective [11]), or it is due to the scarcity and inconclusive nature of the evidence published to date [12-14]. A recently published study offers recommendations on future interventions in this field, such as identifying the impact on the doctors' workload [15].

The Catalan public health system consists of more than 160 providers that offer universal access to 7.5 million people, making it an integrated public welfare network that guarantees the universal right to health [16]. The large number of stakeholders has led centers to create their own information technology (IT) systems to meet specific needs. As a result, in 2008, the decision was made to implement a common platform that can securely share clinical information between different centers and health professionals [17]. Shortly afterward, the personal health folder (PHF), a tool that allows members of the public to securely access their personal information and online services $[18,19]$, was deployed. eConsulta was subsequently launched in 2015 as an asynchronous tele-consultation tool for members of the public and general practitioners (GP) as a complement to face-to-face care. Its implementation has gradually extended to the entire network (more than $92 \%$ of primary care teams have used the tool). Nevertheless, its use in relation to conventional consultations remains low (accounting for just $0.9 \%$ of the total).

A recent study of factors that influence the use of eConsulta found that the main reason individuals used the service was to resolve administrative matters and because the service has potential for significantly reducing the number of face-to-face visits [20]. Another key factor in an effective analysis of the tool's use is establishing the profile of the doctors who use it. Evidence suggests that specific characteristics determine the adoption of digital health technology. Studies have associated older age, close proximity to retirement, and female doctors with a lower probability of the GP using these tools $[6,21,22]$. Additionally, GPs with prior experience with other digital health technologies are shown to be more enthusiastic and optimistic than those who have not yet used them [23].

In light of this evidence, this study aimed to employ a multivariate logistic regression model to analyze the characteristics of GPs that affect their use of eConsulta in the context of the Catalan public health system.

\section{Methods}

\section{Sample}

This is a retrospective descriptive cross-sectional study of primary health care GPs belonging to the Catalan Health Institute (ICS), the major provider of primary care services in Catalonia (serving $74 \%$ of the Catalan population). The period of study was between January 1, 2016, and March 31, 2018. The target sample was made up of all 3259 GPs working at ICS from 285 centers. The following exclusion criteria were established: doctors belonging to centers participating in the pilot phase of the study, those belonging to centers that activated eConsulta less than 12 months after activating the electronic clinical IT system, GPs from centers that activated the eConsulta service after January 2018 (thus ensuring a minimum 2-month use of the service), those with more than 100 children assigned to them, and those who changed primary care teams during the study period. This study included a total of 2451 doctors serving 220 centers (Figure 1). Of these, 808 GPs who were excluded showed no statistically significant difference with respect to age, gender, and their quality of care (QoC) score, which is an indicator based on public information systems that evaluates performance related to the prevention and control of various illnesses such as hypertension, diabetes, and dyslipidemia (Table 1).

The main study variable was the use of the eConsulta service. Use was defined as any messages sent during the study period, and nonuse was defined as no messages sent. The following were considered independent variables: age, gender, socioeconomic level of the center, type of center (rural or urban), average number of adults attended, mean age of patients assigned to GP, percentage of patients who have activated their PHF, GPs involvement in teaching (yes or no), QoC score, pharmacy prescription quality standard (PPQS) score as of December 2017, and doctor's accessibility (possibility of scheduling an appointment within 48 hours, 5 days, and 10 days). 
Figure 1. Flowchart of the study population. NGP: number of general practitioners; NT: number of primary health teams; PCT: primary health team; eCAP: primary care information system; GP: general practitioner.

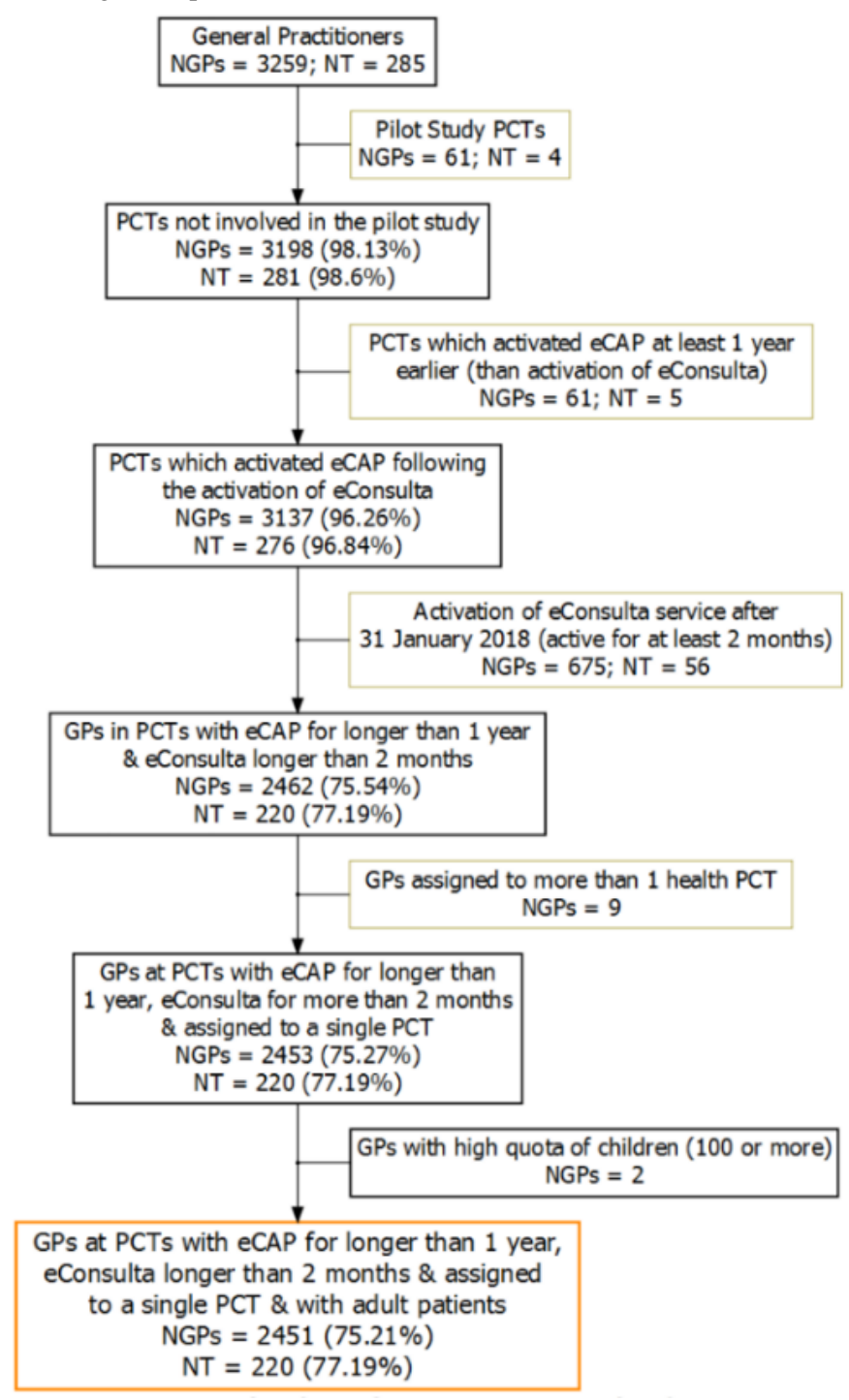

Table 1. Sociodemographic characteristics of doctors included and excluded in the study.

\begin{tabular}{llll}
\hline Demographic & All $(\mathrm{N}=3259)$ & Excluded $(\mathrm{n}=808)$ & Included $(\mathrm{n}=2451)$ \\
\hline Age, $\mathbf{n}(\%)$ & & & $P$ value \\
28-34 years & $184(5.65)$ & $50(6.19)$ & $134(5.47)$ \\
35-44 years & $897(27.50)$ & $243(30.10)$ & $654(26.70)$ \\
45-54 years & $1001(30.70)$ & $227(28.10)$ & $774(31.60)$ \\
55-66 years & $1121(34.40)$ & $271(33.5)$ & $850(34.70)$ \\
Missing & $56(1.72)$ & $17(2.10)$ & $39(1.59)$ \\
Sex, $\mathbf{n}(\%)$ & & & $1660(67.70)$ \\
Male & $2201(67.50)$ & $541(67.00)$ & $752(30.70)$ \\
Female & $1002(30.70)$ & $250(30.90)$ & $39(1.59)$ \\
Missing & $56(1.72)$ & $17(2.10)$ & $762(100)$ \\
Quality of care score & $760(101)$ & $756(102)$ & .61 \\
\hline
\end{tabular}




\section{Model}

The descriptive analysis used the mean and standard deviation for continuous variables and numbers and percentages for categorical variables. The $t$ test was used to test the significance for continuous variables, and the Chi-square test was used for categorical variables. To evaluate which variables make a doctor more likely to have used the platform, a multivariate logistic regression analysis was used with a significance level of $95 \%$. R-3.5.1 (R Foundation for Statistical Computing, Vienna, Austria) software was used to conduct the analysis.

\section{Results}

Table 2 shows the most prevalent characteristics of professional users. Doctors who use eConsulta have a higher percentage of patients who have activated their PHF and score higher on the PPQS score, QoC score, and accessibility of care indices. There are no statistically significant differences between doctors who use eConsulta and those who do not with respect to the average number of adults attended or the average age of the patients assigned to them.

The multivariate regression model examined which variables affect the use of eConsulta. These variables, independently related to the outcome, are distinct from those obtained from the bivariate analysis, in which they are combined. This means it was not possible to identify a specific correlation. The odds ratio for each outcome is shown with regard to the reference categories and can be interpreted as probabilities. A coefficient of less than 1 indicates that the use of eConsulta is less likely, while coefficients greater than 1 indicate a greater probability of the tool being used. Therefore, according to the regression model, the characteristics of the doctors that determine the use of eConsulta include the following: 45-54 years of age, a QoC score that is higher than the 80th percentile, a high degree of accessibility, are involved in teaching, and work in a primary care team in an urban area with a high socioeconomic level. All of the variables shown in Table 3 are statistically significant. 
Table 2. Sociodemographic characteristics of doctors by use of eConsulta.

\begin{tabular}{|c|c|c|c|c|}
\hline Demographic & Total $(\mathrm{N}=2451)$ & User $(n=1269)$ & Nonuser $(\mathrm{n}=1182)$ & $P$ value \\
\hline Sex, n (\%) & & & & $<.001$ \\
\hline Female & $1660(67.70)$ & $798(62.90)$ & $862(72.90)$ & \\
\hline Male & $752(30.70)$ & $439(34.60)$ & $313(26.50)$ & \\
\hline Missing & 39 (1.59) & $32(2.52)$ & $7(0.59)$ & \\
\hline Age, n (\%) & & & & $<.001$ \\
\hline 28-34 years & $134(5.47)$ & $91(7.17)$ & $43(3.64)$ & \\
\hline $35-44$ years & $654(26.70)$ & $326(25.70)$ & $328(27.70)$ & \\
\hline $45-54$ years & $774(31.60)$ & $319(25.10)$ & $455(38.50)$ & \\
\hline $55-66$ years & $850(34.70)$ & $501(39.50)$ & $349(29.50)$ & \\
\hline Missing & $39(1.59)$ & $32(2.52)$ & $7(0.59)$ & \\
\hline Type PCT ${ }^{\mathbf{a}}, \mathbf{n}(\%)$ & & & & $<.001$ \\
\hline OR (Rural) & $227(9.26)$ & $145(11.40)$ & $82(6.94)$ & \\
\hline 1R (Semirural) & $144(5.88)$ & $90(7.09)$ & $54(4.57)$ & \\
\hline 2R (Semiurban) & $270(11.00)$ & $170(13.40)$ & $100(8.46)$ & \\
\hline 4U (Urban, very low socioeconomic level) & $455(18.60)$ & $233(18.40)$ & $222(18.80)$ & \\
\hline 3U (Urban, low socioeconomic level) & $474(19.30)$ & $246(19.40)$ & $228(19.30)$ & \\
\hline 2U (Urban, high socioeconomic level) & $353(14.40)$ & $183(14.40)$ & $170(14.40)$ & \\
\hline $1 \mathrm{U}$ (Urban, very high socioeconomic level) & $528(21.50)$ & $202(15.90)$ & $326(27.60)$ & \\
\hline Type PCT, n (\%) & & & & $<.001$ \\
\hline Rural & $641(26.20)$ & $405(31.90)$ & $236(20.00)$ & \\
\hline Urban & $1810(73.80)$ & $864(68.10)$ & $946(80.00)$ & \\
\hline Adults seen, mean (SD) & $1102(229)$ & $1111(231)$ & $1093(226)$ & .06 \\
\hline Age quota, mean (SD) & $50.1(3.82)$ & $49.9(3.62)$ & $50.3(4.01)$ & .03 \\
\hline Quota for patients aged over 65 years $(\%)$, mean (SD) & $23.6(7.91)$ & $23.2(7.44)$ & $24.1(8.37)$ & .006 \\
\hline Patients with $\mathrm{PHF}^{\mathrm{b}}$ activated (\%), mean (SD) & $5.49(2.85)$ & $4.62(2.31)$ & $6.41(3.08)$ & $<.001$ \\
\hline Teaching in 2017, $\mathrm{n}(\%)$ & & & & $<.001$ \\
\hline No & $2090(85.30)$ & $1123(88.50)$ & $967(81.80)$ & \\
\hline Yes & $361(14.70)$ & $146(11.50)$ & $215(18.20)$ & \\
\hline QoC $^{\mathrm{c}}$ score - December 2017, mean (SD) & $762(100)$ & 749 (108) & $775(89.1)$ & $<.001$ \\
\hline QoC score - December 2017 categorized, n (\%) & & & & $<.001$ \\
\hline $0-20$ & $459(18.70)$ & $302(23.80)$ & $157(13.30)$ & \\
\hline $20-80$ & $1497(61.10)$ & $734(57.80)$ & $763(64.60)$ & \\
\hline $80-100$ & $495(20.20)$ & $233(18.40)$ & $262(22.20)$ & \\
\hline PPQS $^{\mathrm{d}}$ score - December 2017, mean (SD) & $62.1(18.4)$ & $60.7(18.6)$ & $63.5(18.1)$ & $<.001$ \\
\hline PPQS score - December 2017 categorized, n (\%) & & & & $<.001$ \\
\hline $0-20$ & $396(16.20)$ & $213(16.80)$ & $183(15.50)$ & \\
\hline $20-80$ & $1364(55.70)$ & $672(53.00)$ & $692(58.50)$ & \\
\hline $80-100$ & $477(19.50)$ & $203(16.00)$ & $274(23.20)$ & \\
\hline Missing & $214(8.73)$ & $181(14.30)$ & $33(2.79)$ & \\
\hline Replies in less than 5 days (\%), mean (SD) & $67.5(28.60)$ & $75.1(29.80)$ & $65.9(28.10)$ & $<.001$ \\
\hline Accessibility in 48 hours (\%), mean (SD) & $31.1(23.50)$ & $31.7(25.10)$ & $30.5(21.60)$ & .23 \\
\hline
\end{tabular}




\begin{tabular}{lllll}
\hline Demographic & Total (N=2451) & User (n=1269) & Nonuser (n=1182) & $P$ value \\
\hline Accessibility in 5 days (\%), mean (SD) & $50.3(27.80)$ & $48.8(28.80)$ & $51.9(26.60)$ & .006 \\
Accessibility in 10 days (\%), mean (SD) & $74.2(23.70)$ & $71.5(25.10)$ & $77.1(21.80)$ & $<.001$ \\
\hline
\end{tabular}

${ }^{\text {a }} \mathrm{PCT}$ : primary care team.

${ }^{b}$ PHF: personal health folder.

${ }^{\mathrm{c}} \mathrm{QoC}$ : quality of care.

${ }^{\mathrm{d}} \mathrm{PPQS}$ : pharmacy prescription quality standard.

Table 3. Results of the logistic regression model.

\begin{tabular}{lll}
\hline Demographic & Odds ratio (95\% CI) & $P$ values \\
\hline Age: $35-44$ years $^{\mathrm{a}}$ & $2.152(1.431-3.277)$ & $<.001$ \\
Age: $45-54$ years & $2.969(1.979-4.512)$ & $<.001$ \\
Age: $56-66$ years & $1.528(1.019-2.320)$ & .04 \\
Sex: Male & $0.717(0.592-0.869)$ & $<.001$ \\
QoC ${ }^{\text {s }}$ score $20-80 \%$ & $1.942(1.542-2.454)$ & $<.001$ \\
QoC score 80-100\% & $2.329(1.761-3.088)$ & $<.001$ \\
Semirural type & $1.299(0.823-2.047)$ & .26 \\
Semiurban type & $1.158(0.784-1.713)$ & .46 \\
Urban 4: very low socioeconomic level & $2.024(1.410-2.919)$ & $<.001$ \\
Urban 3: low socioeconomic level & $2.038(1.428-2.920)$ & $<.001$ \\
Urban 2: high socioeconomic level & $2.207(1.513-3.231)$ & $<.001$ \\
Urban 1: very high socioeconomic level & $4.016(2.820-5.750)$ & $<.001$ \\
Accessibility in 10 days & $1.017(1.013-1.021)$ & $<.001$ \\
Teaching indicator 2017 & $1.496(1.165-1.923)$ & .002 \\
\hline
\end{tabular}

${ }^{a}$ All variables have a reference category.

${ }^{\mathrm{b}} \mathrm{QoC}$ : quality of care.

\section{Discussion}

The results of this study differ from those of previous ones, which did not find significant differences in the gender and ages of doctors who adopted new technologies as part of their clinical practice $[6,21,22]$. In our sample, these differences can be partially attributed to characteristics of the Catalan ecosystem. For example, in Catalonia, GPs rarely obtain a stable position with their own patients before the former is 30 years of age. Likewise, the lower use of eConsulta in rural areas could be because, in Catalonia, patients' access to health services in rural areas are better than in other regions due to the wide availability of local GP surgeons. The low level of use by younger doctors (30-44 years of age) could be explained by their relatively low level of confidence and security with respect to their patients, while the low level of use by older doctors (56-66 years of age) could be explained by their relatively lower levels of digital competency and their lower incentives to incorporate new elements into their practice due to the close proximity of retirement. The relationship between a higher use of the tool and higher QoC and PPQS scores could be attributed to the doctor's confidence in adopting new tools. In relation to the higher use in urban areas (and possibly as a result of higher socioeconomic levels), it is worth mentioning that this study shows higher socioeconomic groups make more use of new technologies and have greater access to the internet. Primary care teams in areas with a high socioeconomic level have higher PHF activation rates than primary care teams in areas with lower socioeconomic levels

It seems that doctors who use eConsulta more have a higher level of accessibility for face-to-face visits. However, this might be because doctors who use eConsulta are probably more involved in managing their agenda and more prone to meeting QoC and PPQS. The increased waiting time for primary care in Catalonia warrants investigation in other studies.

Other policies may have acted as confounding factors that affected the interpretation of the results. For example, in January 2017, doctors in primary care teams in Barcelona were offered an economic incentive to use eConsulta. It should also be considered that in other instances, the Ministry of Health has introduced incentives to primary care teams throughout Catalonia to increase the use of the PHF.

In summary, these results show that being 45-54 years of age, having a QoC score higher than the 80th percentile, having a high degree of accessibility, being involved in teaching, and 
working in a primary care team in an urban area with a high socioeconomic level are characteristics that determine the use of tele-consultation in Catalonia. This study's data cannot be extrapolated to other health systems; however, the results are critical for digital health policy planners, as the success of the tool will heavily depend on whether GPs promote it.

\section{Acknowledgments}

This study was conducted with the support of the Secretary of Universities and Research of the Department of Business and Knowledge at the Generalitat de Catalunya.

\section{Conflicts of Interest}

None declared.

\section{References}

1. Banks J, Farr M, Salisbury C, Bernard E, Northstone K, Edwards H, et al. Use of an electronic consultation system in primary care: a qualitative interview study. Br J Gen Pract 2017 Nov 06;68(666):e1-e8. [doi: 10.3399/bjgp17x693509]

2. Kierkegaard P. eHealth in Denmark: a case study. J Med Syst 2013 Dec;37(6):9991. [doi: 10.1007/s10916-013-9991-y] [Medline: 24166019]

3. Pearl R. Kaiser Permanente Northern California: current experiences with internet, mobile, and video technologies. Health Aff (Millwood) 2014 Feb;33(2):251-257. [doi: 10.1377/hlthaff.2013.1005] [Medline: 24493768]

4. Zhou YY, Kanter MH, Wang JJ, Garrido T. Improved quality at Kaiser Permanente through e-mail between physicians and patients. Health Aff (Millwood) 2010 Jul;29(7):1370-1375. [doi: 10.1377/hlthaff.2010.0048] [Medline: 20606190]

5. Anderson D, Villagra V, Coman EN, Zlateva I, Hutchinson A, Villagra J, et al. A cost-effectiveness analysis of cardiology eConsults for Medicaid patients. Am J Manag Care 2018 Jan 01;24(1):e9-e16 [FREE Full text] [Medline: 29350511]

6. McGrail KM, Ahuja MA, Leaver CA. Virtual Visits and Patient-Centered Care: Results of a Patient Survey and Observational Study. J Med Internet Res 2017 May 26;19(5):e177 [FREE Full text] [doi: 10.2196/jmir.7374] [Medline: 28550006]

7. Huygens MW, Vermeulen J, Friele RD, van Schayck OC, de Jong JD, de Witte LP. Internet Services for Communicating With the General Practice: Barely Noticed and Used by Patients. Interact J Med Res 2015 Nov 24;4(4):e21 [FREE Full text] [doi: 10.2196/ijmr.4245] [Medline: 26601596]

8. Brant H, Atherton H, Ziebland S, McKinstry B, Campbell JL, Salisbury C. Using alternatives to face-to-face consultations: a survey of prevalence and attitudes in general practice. Br J Gen Pract 2016 May 23;66(648):e460-e466. [doi: 10.3399/bjgp16x685597]

9. Hobbs FDR, Bankhead C, Mukhtar T, Stevens S, Perera-Salazar R, Holt T, et al. Clinical workload in UK primary care: a retrospective analysis of 100 million consultations in England, 2007-14. The Lancet 2016 Jun;387(10035):2323-2330. [doi: 10.1016/s0140-6736(16)00620-6]

10. Goldzweig CL, Orshansky G, Paige NM, Towfigh AA, Haggstrom DA, Miake-Lye I, et al. Electronic patient portals: evidence on health outcomes, satisfaction, efficiency, and attitudes: a systematic review. Ann Intern Med 2013 Nov 19;159(10):677-687. [doi: 10.7326/0003-4819-159-10-201311190-00006] [Medline: 24247673]

11. Farr M, Banks J, Edwards HB, Northstone K, Bernard E, Salisbury C, et al. Implementing online consultations in primary care: a mixed-method evaluation extending normalisation process theory through service co-production. BMJ Open 2018 Mar 19;8(3):e019966 [FREE Full text] [doi: 10.1136/bmjopen-2017-019966] [Medline: 29555817]

12. Atherton H, Pappas Y, Heneghan C, Murray E. Experiences of using email for general practice consultations: a qualitative study. Br J Gen Pract 2013 Nov 01;63(616):e760-e767. [doi: 10.3399/bjgp13x674440]

13. National Institute for Health and Care Excellence. Evidence Standards Framework for Digital Health Technologies. England: NICE; 2019 Mar 01. URL: https://www.nice.org.uk/Media/Default/About/what-we-do/our-programmes/ evidence-standards-framework/digital-evidence-standards-framework.pdf

14. WHO. WHO Guideline: Recommendations on Digital Interventions for Health System Strengthening. Geneva: WHO; 2019 Jan 01. URL: https://apps.who.int/iris/bitstream/handle/10665/311941/9789241550505-eng.pdf?ua=1

15. Atherton H, Brant H, Ziebland S, Bikker A, Campbell J, Gibson A, et al. The potential of alternatives to face-to-face consultation in general practice, and the impact on different patient groups: a mixed-methods case study. Health Serv Deliv Res 2018 Jun;6(20):1-200. [doi: 10.3310/hsdr06200] [Medline: 29889485]

16. García Altés A. Desigualdades Socioeconómicas en Salud. Barcelona: Health Policy Papers CRES; Jan 01, 2017.

17. Fernández O, Domínguez CO, Alés XB. Acceso de los pacientes a su historia clínica electrónica: ventajas e inconvenientes para pacientes y profesionales. FMC - Formación Médica Continuada en Atención Primaria 2017 Oct;24(8):425-427. [doi: 10.1016/j.fmc.2017.04.003]

18. La Meva Salut (Personal Health Folder). URL: https://lamevasalut.gencat.cat/ [accessed 2020-01-21]

19. Departament de Salut. Model D'Atenció No Presencial en el Sistema Sanitari de Catalunya. Barcelona: Departament de Salut; 2014 Jan 01. URL: http://salutweb.gencat.cat/web/.content/ ambits-actuacio/Linies-dactuacio/model assistencial/ MANP2013_2016.pdf 
20. López Seguí F, Vidal-Alaball J, Sagarra Castro M, Garcia Altés A, Garcia Cuyàs F. Does teleconsultation reduce face to face visits? Evidence from the Catalan public primary care system. JMIR Preprints 2020 Mar 01 (forthcoming). [doi: $10.2196 /$ preprints. 14478$]$

21. Lupiañez Villanueva F, Folkvord F, Fauli C. Benchmarking deployment of eHealth among general practitioners. RAND.org 2018 May 30. [doi: 10.2759/511610]

22. Li J, Talaei-Khoei A, Seale H, Ray P, Macintyre CR. Health Care Provider Adoption of eHealth: Systematic Literature Review. Interact J Med Res 2013 Apr 16;2(1):e7 [FREE Full text] [doi: 10.2196/ijmr.2468] [Medline: 23608679]

23. Antoun J. Electronic mail communication between physicians and patients: a review of challenges and opportunities. Fam Pract 2016 Apr 28;33(2):121-126. [doi: 10.1093/fampra/cmv101] [Medline: 26711957]

\author{
Abbreviations \\ GP: general practitioners \\ ICT: information and communication technologies \\ IT: information technology \\ ICS: Catalan Health Institute \\ PHF: personal health folder \\ PPQS: pharmacy prescription quality standard \\ QoC: quality of care.
}

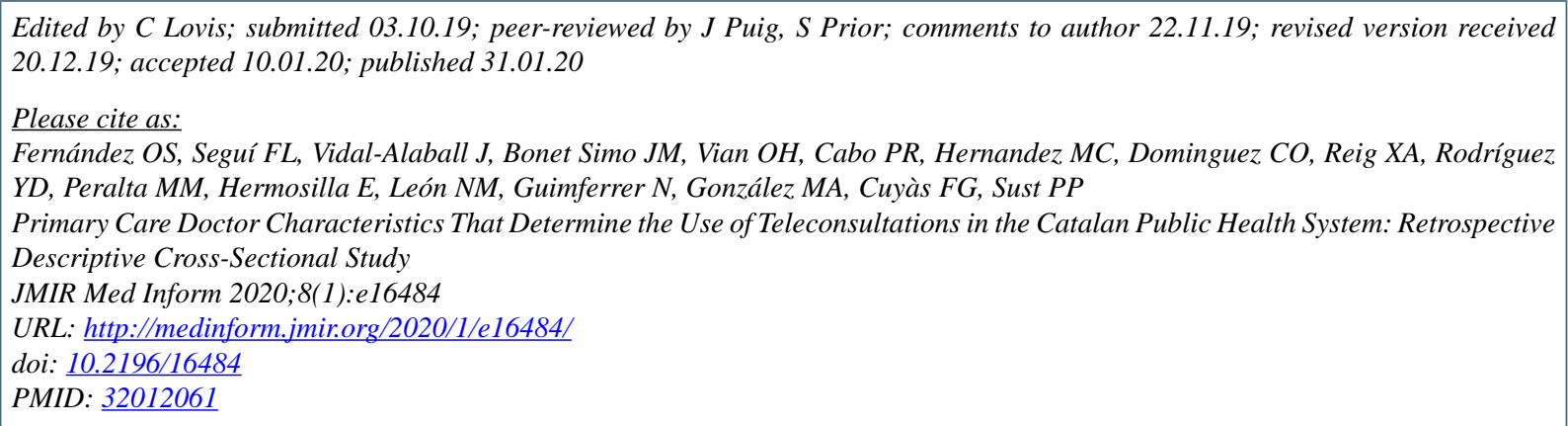

(C) Oscar Solans Fernández, Francesc López Seguí, Josep Vidal-Alaball, Josep Maria Bonet Simo, Oscar Hernandez Vian, Pascual Roig Cabo, Marta Carrasco Hernandez, Carmen Olmos Dominguez, Xavier Alzaga Reig, Yesika Díaz Rodríguez, Manuel Medina Peralta, Eduardo Hermosilla, Nuria Martínez León, Nuria Guimferrer, Mercedes Abizanda González, Francesc García Cuyàs, Pol Pérez Sust. Originally published in JMIR Medical Informatics (http://medinform.jmir.org), 31.01.2020. This is an open-access article distributed under the terms of the Creative Commons Attribution License (https://creativecommons.org/licenses/by/4.0/), which permits unrestricted use, distribution, and reproduction in any medium, provided the original work, first published in JMIR Medical Informatics, is properly cited. The complete bibliographic information, a link to the original publication on http://medinform.jmir.org/, as well as this copyright and license information must be included. 